clearly due to these authors, and I suppose my reference to it as a new feature may only apply to the means I employed-viz., electrolysis. It is intended to demonstrate these features at the Pathological Section of the Royal Society of Medicine shortly.-I am, Sir, yours faithfully,

London, W., March 2nd, 1914.

Charles Russ.

\section{THE AFTER-HISTORY OF A CASE OF SPLENECTOMY.}

To the Editor of THE LANCET.

Sir,--In The LanceT of Sept. 13th, 1913, I reported a case of splenectomy. I beg now to submit the following additional notes.

The patient, who resides in a malarious district, returned to the Colonial Hospital on July 7th, 1913, for the purpose of having his blood examined to note any changes which might have followed the operation. On admission he appeared to be in good health, his weight being $98 \mathrm{lb}$., and no enlargement of the lymphatic glands or any other abnormal condition being found. On the morning of July 12th, while in hospital, he developed an attack of malarial fever which lasted five days. Malarial parasites-benign tertian forms-were found in the blood, and the patient was treated with quinine. On July 22nd, five days after the cessation of the fever, Dr. J. R. Dickson, the bacteriologist to the hospital, kindly examined the blood for me and reported as follows:- "Total count: Red blood corpuscles, 3,800,000 per c.mm.; and white blood corpuscles, 14,000 per c.mm. Differential count, percentages: Polymorphonuclears, 54.2; small 1ymphocytes, 12:2 ; large lymphocytes, 25 ; mononuclears, 4; transitionals, $2 \cdot 8$; and eosinophiles, 1.8." The patient was discharged on July 23rd, and was readmitted on Oct. 8th with a history of fever, headache, giddiness, epistaxis, and malaise for three days. On admission his general condition was good, and examination of the organs revealed nothing of note. His temperature on admission was $99^{\circ} 8^{\circ} \mathrm{F}$.; the tongue was coated with a brown fur and inclined to be dry. Examination of the blood showed the presence of malarial parasites of the subtertian form. The fever: yielded to quinine on Oct. 12th. Six days after the fever had apparently been got rid of the bacteriologist examined the blood and submitted the following notes:- "Total count : Red blood corpuscles, 3,096,300 per c.mm.; white blood corpuscles, 7000 per c.mm.; and hæmoglobin, 78 per cent. Differential count, percentages: Polymorpho nuclears, 56 ; small lymphocytes, 11 ; large lympho; cytes, 13; mononuclears, 13; transitionals, 7 ; and eosinophiles, nil. A total of 320 leucocytes were counted. Many normoblasts were present, some with dividing nucleus." The patient was discharged well on Nov. 8th, and was told to return in three months. His weight on Oct. 30th was $104 \frac{1}{2} \mathrm{lb}$. He came back on Jan. 22nd, 1914, in excellent health, and reported that he had had no fever since his discharge. There was nothing of note to record. Dr. Dickson again very kindly made a blood examination on Jan. 24th, and reported as follows :Total count: Red blood corpuscles. 4,488,000 per c.mm.; white blood corpuscles, 12,000 per c.mm.; and hæmoglobin, $80^{\circ} 0$ per cent. Differential count, percentages: Polymorphonuclears, 54.5; small lymphocytes, $15^{\circ} 0$; large lymphocytes, $12^{\circ} 5$; large mononuculears, 7.5 ; eosinophiles, 100 ; and transitionals, $0{ }^{\circ} 5$. The patient was discharged on Jan. 26th ; his weight on that day was $110 \mathrm{lb}$.

I am, Sir, yours faithfully,

R. SeheulT, M.D. Edin., Feb. 2nd, 1914. Resident Surgeon, Colonial Hospital, Port of Spain,

\section{A NATIONAL MEDICAL SERVICE. To the Editor of THE LANCE'T.}

SIR,-I must leave $\mathrm{Mr}$. C. A. Parker to settle with you as to whether in your reference to the extreme importance of "free choice of doctor" in the recent leading article on a State Medical Service you were discussing the question only from the point of view of the one-sided free choice, an infinitesimal dose of which he now admits is all that could be secured under a whole-time salaried service. But I should like to assure Mr. Parker that I hare no desire to import any prejudice into the consideration of this question. I am convinced that he and his colleagues in the State Medical Service Association are working very earnestly to secure what they consider to be an improvement in medical conditions, and I thought your readers were entitled to get to the bottom of the apparent contradic. tion between the views as to "free choice" expressed by different members of the association when pressing their scheme upon us. To understand this anomaly it seemed necessary first to discover the reason for the hatred of free choice which is openly avowed in many quarters. I believe I am right in attributing it to an honest objection to all forms of competition which is generally found only amongst extreme Socialists and to a real distrust in the growing power and influence of medical men which has frequently been expressed with great vigour by Mr. Bernard Shaw. Nothing will be gained in our discussion by shutting our eyes to these facts. No one worth convincing would oppose a whole-time salaried service if it was for the general good, merely because it also at the same time pleased the very small sections of the community who hold these peculiar views about doctors and competition. Incidentally it is as well, perhaps, that Mr. Parker and others whose views he shares as to the evils of competition should recognise that the establishment of a whole-time salaried service will not abolish competition, but will merely alter its basis. The salaried doctor may not be tempted to please his patient in order to increase his opportunities of doing useful work, but he will certainly be exposed to temptation to please his employer in order to compete with his fellows in securing a better paid or more comfortable job. He may not be tempted to be sympathetic with sick persons in order to increase his remunerative occupation, but he will certainly be tempted to be unsympathetic with them in order to compete with his fellows in securing a greater amount of leisure. Personally I have no fear that for the vast majority of medical men these temptations under a wholetime service would prove detrimental to their good work any more than I believe a temptation to please the patient is a dangerous factor in the panel system, but I claim that those who see dangers of what they call brute competition in one system must not shut their eyes to, or endeavour to bide from us, the existence of similar dangers in the other. But if I am asked whether it is better to run the risk of a doctor being tempted to please a patient or please some person or body employing 